\title{
Resource Sharing Mechanism of National Traditional Sports Curriculum in Colleges and Universities Against the Background of Massive Open Online Course
}

\author{
Aihua Zhang ${ }^{1,{ }^{*}}$ Shunbi $\mathrm{Mu}^{1}$ Shichang $\operatorname{Tian}^{1} \operatorname{Min}_{\mathrm{Chen}}{ }^{1}$ \\ ${ }^{1}$ Institute of Physical Education, Yunnan Normal University, Kunming, Yunnan 650500, China \\ *Corresponding author.
}

\begin{abstract}
This paper uses document literature method, field method and questionnaire surveys to investigate the status quo of traditional ethnic sports curriculum resources in more than $\mathbf{4 0}$ colleges and universities in China. The study finds that the mechanism for sharing traditional national sports curriculum resources in colleges and universities in China is not sound enough; the talent flow mechanism of teachers of physical education courses is not perfect; the venue and equipment resources of traditional ethnic sports courses in colleges are very scarce; the information resources of traditional ethnic sports courses in colleges and universities are incomplete, and the traditional ethnic sports teachers and students in universities need to further improve their awareness of sharing. Through the use of the Massive Open Online Course (MOOC) platform, the exploration of the national traditional curriculum resource sharing mechanism in colleges and universities in China provides a certain reference model for the construction and development of traditional ethnic sports curriculum in China's universities.
\end{abstract}

Keywords: Massive Open Online Course (MOOC) era, national traditional sports, curriculum resources, sharing mechanism

\section{INTRODUCTION}

A. The country promotes cultural development through various paths, inherits and promotes the traditional culture of the Chinese nation; the spread of the traditional sports culture of the nation is a kind of tangible, spiritual, dynamic, and expressive culture

Excellent traditional culture is the treasure of the Chinese nation, the fertile ground on which Chinese civilization has survived for thousands of years, and also an important support for people's inspiring spirit and unity.

General Secretary Xi Jinping delivered an important speech on July 26 in 2017, requiring the entire Party to "firmly establish the self-confidence, theoretical selfconfidence, institutional self-confidence, and cultural self-confidence in the path of socialism with Chinese characteristics, and ensure that the cause of the Party and the state always proceeds in the correct direction". In the "four self-confidences", cultural self-confidence is a more basic, broader, and deeper self-confidence, and it is a kind of more basic, deeper, and more durable

*Fund: The project is supported by the Humanities and Socia Sciences Research and Planning Fund of the Ministry of Education (16YJA890016). force. The provisions of various national holidays to the spread of various cultures, such as ancient poems, music, paintings, calligraphy, etc., are radiated from China to all corners of the world. The spread of national traditional sports culture is also an important and urgent task at present.

B. National traditional sports has its own soil for survival. The culture and survival path expressed in its original way have gradually lost its advantages. Despite various support policies, it is difficult to regain vitality without new motive force of development

Many items of national traditional sports are closely related to their production and life, and modern production and lifestyle have undergone major changes. The original environment of their existence has weakened its practical functions, such as the martial arts defence and attack. Therefore, with the gradual loss of traditional national sports, the propagation and inheritance of its culture are facing many problems. 


\section{The school is an important front for the spread of traditional ethnic sports culture. Although many ethnic sports have entered the campus and cultural propaganda is in full swing, the original driving force for its survival is still lacking}

There are activities of "Ethnic Sports Entering Campus" in universities, middle schools, and primary schools at all levels in China. Many schools, especially colleges and universities, also offer majors in traditional national sports, with theoretical and practical courses. However, in general, the faculty and course construction of these courses are relatively lagging behind. It is necessary to further accelerate the construction and transformation of the thinking of developing national sports in order to push the national traditional sports culture to a wider area.

\section{Against the background of mobile Internet, the development of "Internet plus curriculum" in Chinese universities is still lagging behind, and the development of physical education is the most prominent}

The "Internet + curriculum" model has already begun in foreign countries, Tsinghua University, and Peking University, but the pace of the construction of traditional national sports curriculum is slower in most colleges. The construction of the talent echelon in physical education is relatively weak, and the construction of sports culture is just the short board of the discipline. At the same time, the school physical education curriculum is now mainly established with the "competitive sports curriculum system", and traditional ethnic sports have almost no standing room in schools. Its curriculum construction and development have been marginalized.

Therefore, in this context, it is more necessary to construct a new development strategy and choose a path more suitable for the development of ethnic sports in schools for the development of national traditional sports.

\section{RESEARCH PURPOSES}

In the absence of human resources, curriculum content resources, curriculum quality resources, etc. in traditional ethnic sports courses, the establishment of a platform and mechanism for the development of traditional education in ethnic sports among colleges and universities can be "shared" in order to better inherit the excellent national sports culture, and better inherit and carry forward the cultural heritage and valuable social wealth left by the ancestors.

\section{STATUS QUO OF NATIONAL TRADITIONAL SPORTS CURRICULUM CONSTRUCTION IN COLLEGES AND UNIVERSITIES}

\section{A. Teaching staff of national traditional physical education}

The survey involved 40 colleges and universities nationwide, including: Guizhou University, Guizhou Normal University, Guangxi Normal University, Wuhan Sports University, Lanzhou University, Shaanxi Normal University, Fujian Normal University, etc. Only $14 \%$ of universities mentioned that they have sufficient teachers. It can be seen that the shortage of teachers is quite obvious.

\section{B. Curriculum of national traditional sports}

According to the latest results of the fourth round of physical education evaluations announced by the Degree and Graduate Education Development Center of the Ministry of Education, a total of 54 colleges and universities across the country have opened majors in martial arts and national traditional sports. The first few courses are: martial arts, dragon and lion dance, high foot racing, pearl ball, dragon boat, board shoes racing, etc. From the situation of each school, it all combines its own school characteristics with its specialty programs and general national traditional sports programs. However, with the exception of $95 \%$ of schools offering martial arts and $25 \%$ of schools setting up dragon and lion dance, there are not many repetitive projects.

\section{Status of course delivery}

In the national traditional sports courses offered by colleges and universities, $60 \%$ of them emphasize both technology and theory. The theory mainly teaches movement essentials, technical training, refereeing knowledge, etc., and focuses on the technical level and the meaning of offense and defense; the content of national traditional sports culture is relatively small.

\section{Sharing of course resources}

Combining various forms of WeChat interviews, telephone interviews, and field trips, it can be known that Beijing Sports University, Shanghai University of Sport, and Jishou University all have specialized national traditional sports teachers who work as parttime teachers in multiple schools. Hiring ethnic traditional sports teachers as the main lecturer is the main form of human resources sharing in traditional ethnic sports. $60 \%$ of colleges and universities do not have shared courses and platforms for ethnic traditional sports. Some ethnic traditional sports resources are shared between the college and schools. Most schools have no plans for "resource sharing". 


\section{E. Problems in course resource construction}

1) Insufficient teaching staff: In the understanding of the school teachers, many of the coaches who led the team to participate in the "National Games" are nonprofessional teachers. Some teachers attend classes on a temporary basis, while checking information and training at times.

2) In the construction of curriculum resources, the curriculum system is incomplete, the quality of the curriculum needs to be improved, and there are many obstacles for "resource sharing": Regarding the "resource sharing" of traditional sports courses for ethnic minorities, on the one hand, they encountered many traditional ideological influences, such as martial arts schools, conservative thinking, and old-fashioned plots, making the communication not smooth. At the same time, they do not agree with each other, and do not re-understand the traditional sports culture of the nation as the society changes, to some extent hindering the sharing of traditional sports curriculum resources of ethnic minorities. On the other hand, schools lack of perfect management system and relevant protection awareness for teachers with originality and intellectual property rights, and as a result, teachers can't get protection from intellectual property. This has, to a certain extent, harmed teachers' legitimate rights and interests.

3) There are many objective difficulties in "credit identification" between schools, including many factors such as personnel system reform and curriculum management in colleges and universities: Once "credit recognition" is fully implemented, teachers will face unprecedented pressure, especially for teachers who are not synchronized with school reform and social development. Students may not choose their courses, which means that those teachers "are being laid off". Schools need buffer space, and teachers also need time to improve their ability to adapt to social development through various training and self-improvement methods. However, because of the gaps in the economy, education, and other aspects of the eastern, central, and western regions, the universities in the western regions will inevitably receive great impact. Of course, in the development of traditional national sports, the western region has advantages, but this is based on the collaborative development of national sports by educational institutions, the people's committee, and other departments in the western region. It is necessary to continuously improve the national sports and cultural undertakings, discipline construction, academic echelon, and personnel training levels, however, the top-level design and institutional management can't adapt to the current social changes.
This requires local governments to consolidate their efforts and focus on changing their thinking and paths.

\section{SHARING MECHANISM OF COLLEGE TRADITIONAL SPORTS CURRICULUM CONSTRUCTION}

\section{A. The "echelonization" and "diversity" mechanism of college national traditional sports teachers' sharing}

Judging from the previous investigations, colleges and universities have relatively different traditional sports resources, that is, there is not much duplicate content. But the teacher echelon shows severe age differentiation phenomenon. It is difficult for them to equip themselves with enough teaching staff. At present, the development of traditional ethnic sports is marginalized, and the cost of cultivating talents is also high. If it is classified and cultivated in the form of a certain region or university alliance and if it shares the advantages and strengths of teachers, divided period teaching, training and professional training, then students can enjoy diversified education and it can meet diverse needs through this shared mechanism. The "echelonization" of the training of traditional ethnic sports teachers can also save training costs and ensure the healthy and sustainable development of traditional ethnic sports. It can also avoid vicious competition and extreme development.

\section{B. "Symbiosis" mechanism of college minority student source teams}

Most colleges and universities have part of ethnic minority students. These students are small in number, mostly from economically underdeveloped regions, and their ethnic self-confidence and cultural self-confidence are not enough.But in terms of national culture, only they are the most pure and true "living body of heritage", and they are also the carriers of authentic national culture. The traditional national sports activities are just able to integrate people into their culture with the sound and color and the form and spirit.Schools can use them as the center of a circle, establish a cultural circle, and create a cultural display platform for them. On the one hand, this step can build their national and cultural self-confidence. On the other hand, it can also influence the "intercultural" heritage of student groups interested in their culture so as to form a "symbiotic" mechanism of multi-ethnic cultures and promote mutual development, rather than marginalize or completely alienate one, which is indeed the path of sustainable development of national traditional culture. 


\section{MOOC "exchange credits" mechanism for national traditional sports curriculum in colleges and universities}

Part of the students' studying courses is because of their interest, and some are driven by utilitarian goals. The exchange of credits is beneficial to both students and universities. It is also the best way to keep pace with the times, consider long-term development, and "share and build together" national traditional sports.

Judging from the results of research and the uploaded MOOC, "National Sports, Colorful YunnanAn Outline to the Characteristic Traditional Sports Culture of Ethnic Minorities in Yunnan", since it was launched on June 1, 2019, as of September 17, over the past three months, 6366 people have studied the course, and a certain number of people are increasing every day. Observing the data from the backstage, it can be seen that some students still repeatedly watch videos and work problems because of making error when doing homework, which can be regard as a kind of behavior without any utilitarian goals. Some people still insist on learning. The author, personally, think that these people should be really interested in the content of the course. There is no mechanism for "exchange of credits" or "recognition of credits". It can be seen that the prospect of the MOOC of the national traditional physical education course is still considerable.

\section{D. "Sharing and mutual assistance" development mechanism for national sports courses in colleges and universities as well as local national cultural industries}

If college students only study a certain type of national traditional sports course in school, and do not think about the way in which traditional national sports are rooted in society and ethnic areas, the curriculum learning is out of touch with the long-term development of national traditional sports, and its vitality is extremely fragile.Relying on the support of the state alone and without "native power" for the development of traditional national sports, it will always be eliminated by history. Because of this, its development must be linked to local national life and cultural industries, which needs magic breathe and to be down to earth to take the development mechanism of "shared and mutual assistance".

\section{E. Convenient "information conversion" sharing mechanism for "cross-cultural communication" of national traditional sports in colleges and universities}

In the process of social development, the phenomenon that often appears is "interracial attraction", that is, the cultural attraction of "different nations", which can be fully explained by Maslow's Hierarchy of Needs Theory. Owned culture, because its needs are met, and it won't be expressed as an urgent need. Because of lack of knowledge as well as having interest in the culture of other nations, it becomes an urgent need. Whether it is language, music, dance, sports or other things, it will show such characteristics.

Therefore, it is feasible to consider the "crosscultural" transmission or inheritance path of "interethnic" national traditional sports. The biggest obstacle is the "poor communication of information". If the "convenient information conversion" channel can be opened, its sharing mechanism can be spread among different nationalities, universities, and even different countries and the area where its national traditional sports are spread and inherited will undergo drastic changes.

\section{F. Sharing mechanism of "cross-border mutual dissolution" of national traditional sports festivals in colleges and universities}

The spread of traditional ethnic sports culture can also be promoted through the sharing mechanism of "cross-border mutual dissolution". For example, colleges and universities send teachers to support education in minority areas, teach children to learn cultural knowledge in minority areas, and learn about the culture of other nationalities. After returning to their own school, teachers can return to school to lead students to minority areas to celebrate minority festivals, or they can lead students to participate in some school celebrations through the "Bridge Construction" mechanism. Similarly, some ethnic traditional sports programs are carried out in tourist attractions, characteristic sports towns, and ethnic demonstration villages. Students can go on-site inspections, participate in, and even organize and bring more people to experience. Their successors can come to the school stage to show people the oldest, primitive or interesting national traditional sports activities, stories, etc. This can be more rewarding than ordinary teachers' dry lectures.

\section{CONCLUSIONS AND RECOMMENDATIONS}

\section{A. Conclusions}

First, the construction of national traditional sports curriculum resources is still in its infancy.

Second, the overall equipment of teachers is insufficient, and the recruitment of ethnic traditional sports teachers among universities as the main lecturer is the main form of human resources sharing in traditional ethnic sports.

Third, departments related to traditional ethnic sports culture in colleges and universities, such as the Education Department, the Sports Bureau, and the State Ethnic Affairs Commission, have not fully exerted the 
role of "top-level design." Among colleges, there are still many constraints on the "resource sharing" of traditional ethnic sports. It is necessary to break the outmoded conventions and move faster.

Fourth, the "resource sharing mechanism" of the traditional ethnic sports curriculum relies on multisectoral cooperation to solve the barriers of "recognition of credits" among colleges and universities, and it also needs the necessary institutional guarantee.

\section{B. Recommendations}

First, the construction of national traditional sports curriculum resources must form a "resource sharing" thinking, integrate curriculum resources from the toplevel design, highlight features and advantages, and establish a curriculum team to improve the quality of curriculum construction. If educational institutions can cooperate with multiple universities to complete the integration, construction and sharing of curriculum resources, it will be an important link in the construction of national traditional sports specialty in universities. It is also the best choice for the development of national traditional sports culture.

Second, it is necessary to establish a "credit transfer" system in colleges and universities to protect the vital interests of teachers.

Third, it is suggested that the State Ethnic Affairs Commission and the Sports Bureau should accelerate the "information transformation channel" for communication among different ethnic groups in promoting communication among the people, schools, students and society, and promote "cross-cultural" communication and form the "cross-border" heritage and development of national traditional sports culture.

Fourth, multiple departments must unite to create a national traditional sports culture circle, build multiple paths for the survival and development of traditional national sports culture, form a "symbiotic system" of culture, and enable healthy and sustainable development of culture.

\section{References}

[1] Peng Li, Liu Zhonghua. Research on the Development of Traditional Sports of Ethnic Minorities Against the Background of the Networking Era [J]. Traditional Chinese Sports, 6 (3): 9091. (in Chinese)

[2] Bai Ling, Wang Xiaoying, Huang Meng. Construction of University Curriculum Resources in the Network Age $[\mathrm{J}]$. Teaching Theory, 2014: 121-123. (in Chinese)

[3] Peng Li, Liu Zhonghua. Research on the Development of Traditional Sports of Ethnic Minorities Against the Background of the Networking Era [J]. Traditional Chinese Sports, 2013, 6 (3): 89-92. (in Chinese)
[4] Song Chunhong, Lu Cuilian. Discussion on the Promotion of Traditional Sports of Ethnic Minorities Based on the Internet Age [J]. Journal of Hubei Correspondence University, 2016, 29 (11): 76-77. (in Chinese)

[5] Bai Ling, Wang Xiaoying, Huang Meng. Construction of University Curriculum Resources in the Network Age. Chinese Adult Education [J] 2014,4: 121-123. (in Chinese)

[6] Zhong Xiaoliu, Song Shuqiang, Jiao Lizhen. Research on the teaching design based on the concept of flipped classroom in the information environment [J]. Open Education Research, 2013 (2). (in Chinese)

[7] Li Yang. The Value and Dilemma of Developing National Traditional Sports Courses in Colleges and Universities. Sports Science and Technology [J] 2016,37, (4): 160-161. (in Chinese)

[8] Peng Li, Liu Zhonghua. Research on the Development of Traditional Sports of Ethnic Minorities in the Age of Networking [J]. Traditional Chinese Sports, 2013, 6 (3): 89-92. (in Chinese)

[9] Song Chunhong, Lu Cuilian. Discussion on the Promotion of Traditional Sports of Ethnic Minorities Based on the Internet Age [J]. Journal of Hubei Correspondence University, 2016, 29 (11): 76-77. (in Chinese)

[10] Zhang Aihua et al. SWOT analysis of traditional traditional physical education curriculum resource sharing in the context of "MOOC" [J]. Sports World (Academic Edition), 2018, 12:80. (in Chinese) 